\title{
Keterlibatan Kader Dalam Keberlangsungan Program Kesehatan Masyarakat (Studi Literatur)
}

Zahra Anggita Pratiwi ${ }^{1)}$

Politeknik Kesehatan TNI AU Adisutjipto

Email: zpratiwia@gmail.com

\begin{abstract}
Community health workers (CHWs) are in a unique position between society and the health system. Although CHWs are positioned as the front line team for the extension of government programs in the community, there are no best practices in implementing community-based programs. This study aims to provide descriptive recommendations for the best CHW involvement models in the implementation of health programs. This research is a study of a number of related literatures that emphasize the community approach. The success of the program relates to trained resources and good supervision. The performance and motivation of the CHWs are also not a separate part of the program's sustainability. Meanwhile, the CHW remuneration system is another factor. CHWs involved in public health services generally have a desire for self-development, a spirit of contribution to health improvement, better use of free time, and a belief that they will be rewarded by God. This research focuses on two important recommendations. First, it is necessary to develop a best practical model for community-based programs. Second, it is necessary to advocate for appreciation and support for the role of CHWs in the program's sustainability.
\end{abstract}

Keyword: Community Health Workers, Sustainability of Programs, Community-based Programs

\begin{abstract}
ABSTRAK
Kader berada dalam posisi unik antara masyarakat dan sistem kesehatan. Meskipun kader ditempatkan sebagai tim garis depan perpanjangan tan-gan program pemerintah di tengah masyarakat, namun belum ada praktik terbaik dalam pelaksanaan program berbasis masyarakat. Penelitian ini bertujuan memberikan rekomendasi deskriptif model keterlibatan kader terbaik dalam pelaksanaan program kesehatan. Penelitian ini merupakan kajian sejumlah literatur terkait yang menitikberatkan pendekatan ma-syarakat. Keberhasilan program terkait pada sumber daya terlatih dan supervisi yang baik. Performa dan motivasi kader juga bukan bagian ter-pisah dari keberlangsungan program. Sementara, sistem renumerasi kader merupakan faktor pertimbangan lain. Kader terlibat dalam layanan kesehatan masyarakat umumnya memiliki keinginan untuk pengembangan diri, semangat kontribusi perbaikan kesehatan, pemanfaatan waktu luang yang lebih baik, dan kepercayaan mendapat pahala dari Tuhan. Penelitian ini fokus pada rekomendasi dua hal penting. Pertama, perlu penyusunan model praktis terbaik program berbasis masyarakat. Kedua, perlu advokasi penghargaan dan dukungan untuk peran kader dalam keberlangsungan program.

Kata Kunci: Kader Kesehatan, Keberlangsungan Program, Program Kesehatan Masyarakat
\end{abstract}




\section{PENDAHULUAN}

Keberlangsungan program kesehatan berbasis masyarakat dipengaruhi oleh banyak faktor. Penyampaian layanan kesehatan terutama untuk masyarakat pedesaan atau daerah tak terjangkau banyak melibatkan kader. Alasan melibatkan kader karena kader memiliki posisi unik di antara masyarakat dan sistem kesehatan (Kok, Broerse, et al 2017, Kok, Ormel, et al 2017). Kader berperan sebagai penghubung komunitas dan penyedia layanan Kesehatan (Falbe et al 2017, Musinguzi et al 2017), bahkan kader diekspektasikan dapat menyediakan informasi untuk pejabat kesehatan berwenang yang mungkin tidak dapat mencapai masyarakat secara langsung (Iswarawanti 2010).

Banyak program kesehatan memposisikan kader dalam peran vital, terutama dalam hal penjangkauan (outreach), dan engagement activities dalam masyarakat (Benson et al 2017, King et al 2017). Peran kader di Indonesia tercatat dalam Peraturan Menteri Dalam Negeri No 54 Tahun 2007 tentang Pedoman Pembentuan Kelompok Kerja Operasional Pembinaan Pos Pelayanan Terpadu. Kader Posyandu berperan dalam penyelenggaraan Posyandu, termasuk mobilisasi sumber daya masyarakat, mengadvokasi masyarakat serta membangun kemampuan lokal (Iswarawanti 2010)Karakteristik kader dalam program kesehatan sangat bervariasi. Satu hal yang pasti adalah mereka bagian dari masyarakat (Falbe et al 2017, Kok, Ormel, et al 2017). Program kesehatan melibatkan kader, karena mereka adalah bagian dari masyarakat yang berperan sebagai motivator, komunikator dan perpanjangan tangan pemerintah dalam layanan kesehatan (Falbe et al 2017).

Peran penting kader dalam program kesehatan masyarakat memberikan urgensi untuk mengetahui fakor apa dan bagaimana mengendalikan keberlangsungan program. Penelitian menunjukkan bahwa motivasi dan komitmen merupakan faktor internal kader yang memengaruhi keterlibatan dan keberlangsungan program (Kok, Ormel, et al 2017). Kesempatan mengikuti kegiatan pelatihan merupakan salah satu cara membangun komitmen kader (Iswarawanti 2010, Susanto et al 2017). Namun, keberadaan kader di lapangan masih labil, karena ppartisipasi kader yang bersifat sukarela, sehingga tidak menjamin bahwa kader akan tetap menjalankan fungsinya dengan baik (Profita 2018).

Performa kader dalam memberikan layanan kesehatan bergantung pada dukungan supervisor dan hubungan baik dengan tenaga kesehatan lain (Ludwick et al 
2018, Mays et al 2017). Namun, bentuk pelaksanaan supervisi yang seperti apa perlu dipertimbangkan. Peneliti memandang perlu ada praktik terbaik dalam pelaksanaan program berbasis masyarakat.

\section{METODE PENELITIAN}

Penelitian deskriptif ini merupakan penelitian studi literatur. Studi literatur adalah serangkaian kegiatan yang berkenaan dengan metode pengumpulan data pustaka, membaca, dan mencatat, serta mengelola bahan penelitian yang berhubungan dengan topik yang diangkat dalam penelitian.

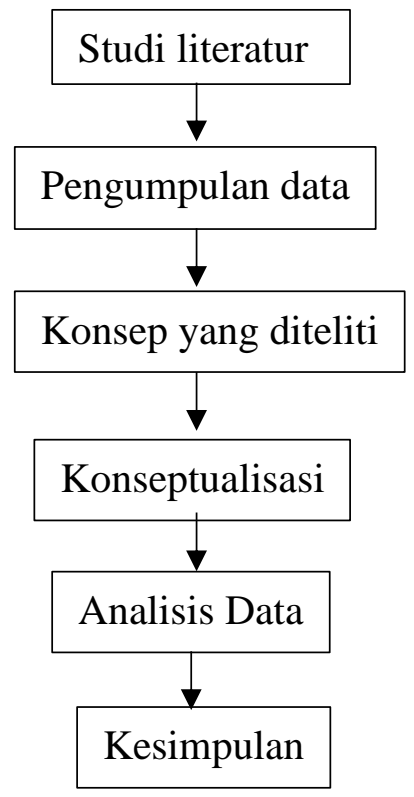

Gambar 1. Alur Penelitian
Artikel-artikel jurnal yang terkumpul akan direduksi dengan batasan artikel yang diikutsertakan adalah artikel yang terbit pada rentang 2013 sampai 2018. Kriteria yang digunakan dapat dibagi menjadi dua macam. Kriteria pertama adalah kelengkapan artikel dan bahasa. Artikel ilmiah yang dipilih adalah artikel yang diterbitkan dalam bahasa Inggris dan utuh. Manuskrip dipandang utuh, jika memuat judul, nama pengarang, penerbit, abstrak, serta terdapat isi artikel yang lengkap hingga daftar pustaka. Kriteria kedua adalah relevansi. Penelitian ini berbatas pada artikel penelitian yang melibatkan kader dengan program preventif dan terkait performa dan motivasi kader.

Metode pengumpulan data dilakukan dengan cara mendeskripsikan fakta-fakta yang ditemukan pada artikel penelitian. Metode yang digunakan yaitu sebagai berikut: 1) Penelusuran database elektronik (Pubmed dan Cohrane); 2) Pencarian artikel pada jurnal berbahasa Inggris yang relevan dan kredibel yaitu Human Resources for Health. Kata kunci pencarian pada database Pubmed, Cohrane dan website jurnal Human Resources for Health adalah community health worker dengan mempertimbangkan penelusuran menggunakan MeSh (Medical Subject Headings). MeSh merupakan 
pengaturan pendaftaran kata kedalam sebuah daftar kata (atau sistem metadata) untuk penggunaan indekfikasi artikel-artikal jurnal dan buku dalam ilmu kesehatan.

Penelitian menggunakan analisis induktif, yaitu proses pembahasan berasal dari pola dari data dan bukan ditentukan sebelum penelitian berlangsung. Analisis data pada penelitian ini terdiri dari tiga tahap yaitu: 1) Reduksi data adalah proses pemilihan, pemusatan perhatian pada penyederhanaan, pengabstrakan, dan transformasi data kasar yang muncul; 2) Penyajian data: Peneliti menyajikan datadata dalam bentuk deskripsi narasi atau tabel berdasarkan aspek yang diteliti; 3) Penarikan kesimpulan/ verifikasi: kesimpulan diambil secara bertahap.

\section{HASIL DAN PEMBAHASAN}

Penelitian ini mencakup 24 artikel yang terdiri dari: 10 artikel dari Pubmed, 4 artikel dari Cohrane, dan 10 artikel dari jurnal Human Resource of Health. Gambar 2 menunjukkan strategi pencarian yang disajikan menggunakan PRISMA flow diagram (Gambar 2). Program kesehatan yang melibatkan kader dalam hasil review ini adalah program KIA, hidup sehat dan aktivitas fisik, serta malaria. Hasil review menunjukkan cakupan beban kerja kader sangat beragam. Beberapa program menekankan kader untuk program dan komunitas lebih spesifik. Kader dianggap dekat dengan masyarakat, sehingga segala bentuk layanan kesehatan semua dibebankan pada mereka.

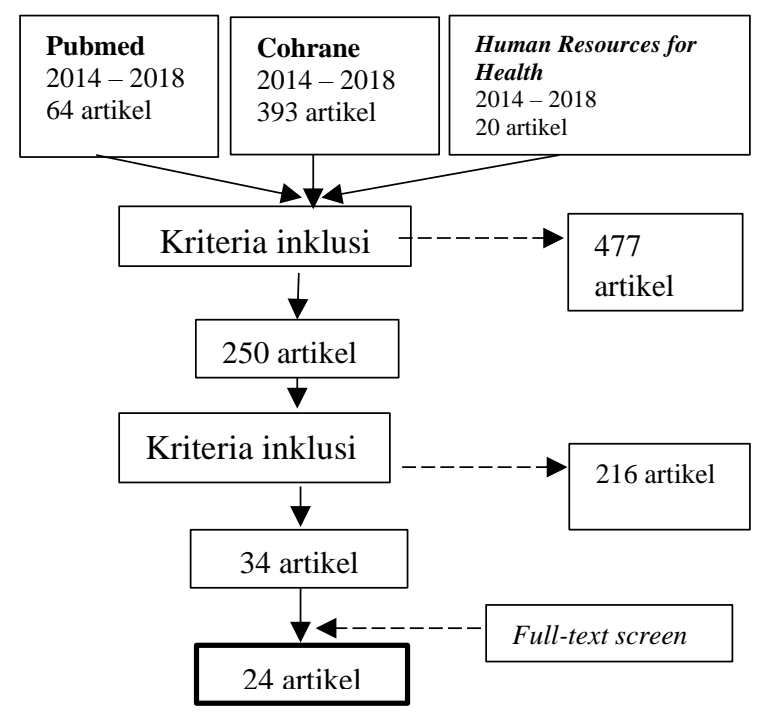

Gambar 2. PRISMA Flow diagram

Hasil review menunjukkan bahwa semua kader yang terlibat program kesehatan masyarakat mendapatkan pelatihan, meskipun bentuk dan lama pelatihan itu sangat bervariasi. Hanya satu artikel yang tidak mendefinisikan supervisor. Bentuk pengawasan kader pun sangat beragam. Mayoritas supervisor adalah tenaga kesehatan formal (Tabel 1).

Kemitraan dan pendekatan masyarakat melalui tim komunitas (kader, supervisor, pemimpin/tokoh masyarakat, tokoh agama, dan bagian masyarakat lain) merupakan kunci keberlanjutan program 
(Lunsford, Fatta, Stover, \& Shrestha, 2015; Musinguzi et al., 2017). Namun, inovasi intervensi seharusnya mempertimbangkan spesifik outreach dan media edukasi tepat (seperti bermain drama, siaran radio, pertemuan rutin) pada setiap setting dan target populasi (Benson et al., 2017). Cakupan intervensi spesifik dapat menentukan dasar seperti apa pelatihan kader, sehingga akan membantu memastikan intervensi konsisten.

Tabel 1. Perbandingan model keterlibatan kader berdasarkan negara

\begin{tabular}{|c|c|c|c|c|c|}
\hline Country & The term community health worker & Training & Salary & Supervisor & Kurikulum \\
\hline Zambia & Community Health Assistant (CHA) & $\mathrm{v}$ & $\mathrm{V}$ & $\mathrm{v}$ & TT \\
\hline Kenya & CHWs & $\mathrm{v}$ & $\mathrm{x}$ & $\mathrm{v}$ & TT \\
\hline Papua New Guinea & Cadre & $\mathrm{v}$ & $\mathrm{v}$ & $\mathrm{v}$ & $\mathrm{V}$ \\
\hline Uganda & Village Health Teams (VHT) & $\mathrm{v}$ & $\mathrm{x}$ & $\mathrm{v}$ & TT \\
\hline $\begin{array}{l}\text { Southwestern United } \\
\text { States }\end{array}$ & Navajo CHWs & $\mathrm{v}$ & $\mathrm{v}$ & $\mathrm{v}$ & $\mathrm{v}$ \\
\hline Mozambique & Village Health Teams (VHT) & $\mathrm{v}$ & $\mathrm{v} / \mathrm{x}$ & $\mathrm{v}$ & $\mathrm{V}$ \\
\hline & CHWs & $\mathrm{v}$ & $\mathrm{x}$ & $\mathrm{v}$ & $\mathrm{V}$ \\
\hline Tanzania & $\begin{array}{l}\text { Government-endorsed Home-based care } \\
\text { (HBC) volunteers }\end{array}$ & $\mathrm{v}$ & TT & $\mathrm{v}$ & TT \\
\hline Etiopia & Health extention workers (HEWs) & $\mathrm{v}$ & $\mathrm{V}$ & $\mathrm{v}$ & $\mathrm{X}$ \\
\hline Malawi & Health Surveillance Assistants (HSAs) & $\mathrm{v}$ & $\mathrm{V}$ & $\mathrm{v}$ & TT \\
\hline Nepal & $\begin{array}{l}\text { Female Community Health Volunteers } \\
\text { (FCHA) }\end{array}$ & $\mathrm{v}$ & $\mathrm{x}$ & $\mathrm{v}$ & TT \\
\hline Bangladesh & Community Health Volunteers (CHA) & $\mathrm{v}$ & $\mathrm{x}$ & $\mathrm{v}$ & $\mathrm{TT}$ \\
\hline India & Accredited Social Health Activist (ASHA) & $\mathrm{v}$ & $\mathrm{v} / \mathrm{x}$ & $\mathrm{x}$ & $\mathrm{V}$ \\
\hline America Latin & Promotora & $\mathrm{v}$ & $\mathrm{v}$ & TT & $\mathrm{V}$ \\
\hline Pakistan & Lady Health Workers (LHWs) & $\mathrm{v}$ & $\mathrm{TT}$ & $\mathrm{v}$ & TT \\
\hline
\end{tabular}

Keterangan : $\mathrm{TT}=$ tidak terdefinisi 
Pelatihan kader merupakan salah satu bentuk penjaminan kualitas intervensi kesehatan masyarakat, cost-effective (Benson et al 2017, Brenner et al 2017, Pilang et al 2017), dan salah satu motivasi keterlibatan kader dalam program (Rabbani et al 2016). Sementara, bagaimana strategi mempertahankan peran kader merupakan kunci utama (Brenner et al 2017).

Beberapa keberhasilan program berkaitan dengan keterlibatan kader yang tersertifikasi dan memiliki kurikulum yang dituangkan dalam modul (King et al 2017, Phiri et al 2017, Pilang et al 2017, Raffo et al 2017). Motivasi merupakan faktor internal kader yang memengaruhi keterlibatan dan keberlangsungan program. Penelitian menunjukkan bahwa motivasi kader lebih baik saat bentuk supervisi adalah supportive supervision (Kok, Ormel, et al 2017, Ludwick et al 2018, Rabbani et al 2016). Selain itu, inovasi supervisi seperti menggunakan teknologi merupakan salah satu jalan efektivitas program (Aridi et al 2014). Peningkatan supervisi dapat dilakukan saat kunjungan lapangan (tatap muka dengan kader) dan melalui mekanisme monitoring berkala (Ndima et al 2015). Sementara, pendekatan inovasi untuk meningkatkan motivasi kader adalah dengan memanfaatkan supervisi berbasis teknologi
(mHealth) dan participatory community engagement (Källander et al 2015).

Selain faktor internal seperti motivasi, faktor eksternal untuk optimalisasi dampak kader dalam program berbasis masyarakat mencakup sistem pengawasan, insentif atau renumerasi, dan sistem pelaporan yang baik (Phiri et al 2017). Situasi sosio-ekonomi, partisipasi masyarakat, kesukarelaan dan peran tokoh masyarakat memengaruhi performa kader dalam memberikan layanan kesehatan (Kok, Broerse, et al 2017). Kapasitas dan motivasi kader untuk memberikan layanan kesehatan bergantung pada pengetahuan, keahlian, nilai hidup dan tujuan (Kok, Ormel, et al 2017). Partisipasi dan keleluasaan kader dalam menyampaikan pendapat adalah hal lain yang perlu dipertimbangkan (Madede $e t$ al 2017). Di sisi lain, penelitian menyimpulkan bahwa motivasi kader terlibat dalam program adalah keinginan menolong, merasa mendapat kepercayaan dari masyarakat dan merasa puas terhadap kontribusi kesehatan di lingkungan (Kok, Ormel, et al 2017, Strachan et al 2015, Winn et al 2018). Temuan penelitian lain menunjukkan bahwa percaya mendapat pahala dari Tuhan adalah faktor pendukung kuat motivasi kader daripada faktor eksternal seperti renumerasi dan 
mendapatkan penghormatan dari komunitas (Mpembeni et al 2015). Motivasi dan kinerja kader ini berpotensi meningkatkan cakupan strategi delivery program dan mewujudkan program kesehatan yang berkelanjutan (Källander et al 2015).

Efektivitas program tidak hanya bergantung pada motivasi dan kepuasan kader, tetapi juga pada tingkat beban kerja mereka (Winn et al 2018). Penelitian di Uganda menunjukkan bahwa ekspektasi masyarakat terhadap kader berperan dalam keinginan kader terlibat dalam program (Musinguzi et al 2017). Kesuksesan dan keberlangsungan program membutuhkan rancangan dan manajemen program yang efektif, termasuk deskripsi tugas yang jelas, proses rekrutmen terstruktur, pelatihan, renumerasi, penerimaan komunitas, dan dukungan pemerintah (Aridi et al 2014, Kok, Broerse, et al 2017, Pallas et al 2013).

Penetapan proses rekrutmen harus menjelaskan kriteria kandidat kader secara tertulis dan harus dijelaskan sebelum proses rekrutmen berlangsung (Aridi et al 2014). Selanjutnya, pelaksana program harus mempertimbangkan untuk menyediakan paket kompensasi kader. Renumerasi memungkinkan kader termotivasi untuk meningkatkan komitmen mereka terhadap tanggung jawab yang diberikan (Greenspan et al 2013). Namun, renumerasi yang diberikan harus mempertimbangkan beban kerja (Aridi et al., 2014). Dukungan insentif transportasi dan kemitraan yang baik antara kader dan tenaga kesehatan lain merupakan kunci pemerataan akses layanan kesehatan (Mays et al 2017).

Penelitian studi kasus di lima negara menunjukkan bahwa baik kader yang mendapatkan renumerasi, maupun kader sukarela memiliki potensi berkontribusi efektif pada program berbasis masyarakat. Sebagai contoh, kader sukarela yang memiliki supervisor, terlatih, dan bekerja penuh waktu dengan menerima pembayaran rutin, atau kombinasi keduanya lebih mungkin melibatkan masyarakat dalam pemberdayaan yang berhubungan dengan kesehatan (Singh et al 2015).

\section{KESIMPULAN}

Penelitian ini fokus pada rekomendasi dua hal penting. Pertama, perlu penyusunan model praktis terbaik program berbasis masyarakat. Kedua, perlu advokasi penghargaan dan dukungan untuk peran kader dalam keberlangsungan program.

\section{DAFTAR PUSTAKA}

Aridi JO, Chapman SA, Wagah MA and Negin J (2014) A comparative study of an NGO-sponsored $\mathrm{CHW}$ programme versus a ministry of health sponsored 
CHW programme in rural Kenya: A process evaluation. Human Resources for Health. BioMed Central 12(1): 64.

Benson A, Calhoun LM, Corroon M, Lance P, O'Hara R, Otsola J, Speizer IS, Winston J, Measurement other members of the $\mathrm{K}$ and Team L\& EP (2017) Longitudinal Evaluation of the Tupange Urban Family Planning Program in Kenya. International perspectives on sexual and reproductive health. $\mathrm{NIH}$ Public Access 43(2): 75-87.

Brenner JL, Barigye C, Maling S, Kabakyenga J, Nettel-Aguirre A, Buchner D, Kyomuhangi T, Pim C, Wotton K, Amon N and Singhal N (2017) Where there is no doctor: can volunteer community health workers in rural Uganda provide integrated community case management? African health sciences. Makerere University Medical School 17(1): 237-246.

Falbe J, Friedman LE, Sokal-Gutierrez K, Thompson HR, Tantoco NK and Madsen KA (2017) "She Gave Me the Confidence to Open Up": bridging Communication by Promotoras in a Childhood Obesity Intervention for Latino Families. Health education \& behavior 44(5): 728-737.

Greenspan JA, McMahon SA, Chebet JJ, Mpunga M, Urassa DP and Winch PJ (2013) Sources of community health worker motivation: A qualitative study in Morogoro Region, Tanzania. Human Resources for Health. Human Resources for Health 11(1): 1.

Iswarawanti DN (2010) Kader Posyandu: peran dan tantangan pemberdayaannya dalam usaha peningkatan gizi anak di Indonesia. Jurnal Manajemen Pelayanan Kebijakan 13(4): 169-173.
Källander K, Strachan D, Soremekun S, Hill Z, Lingam R, Tibenderana J, Kasteng F, Vassall A, Meek S and Kirkwood B (2015) Evaluating the effect of innovative motivation and supervision approaches on community health worker performance and retention in Uganda and Mozambique: Study protocol for a randomised controlled trial. Trials. BioMed Central 16(1): 157.

King C, Goldman A, Gampa V, Smith C, Muskett O, Brown C, Malone J, Sehn H, Curley C, Begay MG, Nelson AK and Shin SS (2017) Strengthening the role of Community Health Representatives in the Navajo Nation. BMC Public Health. BMC Public Health 17(1): 1-10.

Kok MC, Broerse JEW, Theobald S, Ormel $\mathrm{H}$, Dieleman $\mathrm{M}$ and Taegtmeyer $\mathrm{M}$ (2017) Performance of community health workers: Situating their intermediary position within complex adaptive health systems. Human Resources for Health. Human Resources for Health 15(1): 1-7.

Kok MC, Ormel H, Broerse JEW, Kane S, Namakhoma I, Otiso L, Sidat M, Kea AZ, Taegtmeyer $\mathrm{M}$, Theobald $\mathrm{S}$ and Dieleman M (2017) Optimising the benefits of community health workers' unique position between communities and the health sector: A comparative analysis of factors shaping relationships in four countries. Global Public Health. Taylor \& Francis 12(11): 1404-1432.

Ludwick T, Turyakira E, Kyomuhangi T, Manalili K, Robinson S and Brenner JL (2018) Supportive supervision and constructive relationships with healthcare workers support $\mathrm{CHW}$ performance: Use of a qualitative framework to evaluate $\mathrm{CHW}$ programming in Uganda. Human 
Resources for Health. BioMed Central 16(1): 11 .

Madede T, Sidat M, McAuliffe E, Patricio SR, Uduma O, Galligan M, Bradley S and Cambe I (2017) The impact of a supportive supervision intervention on health workers in Niassa, Mozambique: a cluster-controlled trial. Human resources for health 15(1): 58. Available at:

https://www.cochranelibrary.com/centra 1/doi/10.1002/central/CN-

01604214/full.

Mays DC, O’Neil EJ, Mworozi EA, Lough BJ, Tabb ZJ, Whitlock AE, Mutimba EM and Talib ZM (2017) Supporting and retaining Village Health Teams: An assessment of a community health worker program in two Ugandan districts. International Journal for Equity in Health. BioMed Central 16(1): 129.

Mpembeni RNM, Bhatnagar A, LeFevre A, Chitama D, Urassa DP, Kilewo C, Mdee RM, Semu H, Winch PJ, Killewo J, Baqui AH and George A (2015) Motivation and satisfaction among community health workers in Morogoro Region, Tanzania: nuanced needs and varied ambitions. Human resources for health. BioMed Central 13: 44.

Musinguzi LK, Turinawe EB, Rwemisisi JT, de Vries DH, Mafigiri DK, Muhangi D, de Groot M, Katamba A and Pool R (2017) Linking communities to formal health care providers through village health teams in rural Uganda: Lessons from linking social capital. Human Resources for Health. BioMed Central 15(1): 4.

Ndima SD, Sidat M, Give C, Ormel H, Kok MC and Taegtmeyer M (2015) Supervision of community health workers in Mozambique: A qualitative study of factors influencing motivation and programme implementation. Human Resources for Health. Human Resources for Health 13(1): 1-10.

Pallas SW, Minhas D, Pérez-Escamilla R, Taylor L, Curry L and Bradley EH (2013) Community health workers in low- and middle-income countries: What do we know about scaling up and sustainability? American Journal of Public Health 103(7): 74-82.

Phiri SC, Prust ML, Chibawe CP, Misapa R, van den Broek JW and Wilmink $\mathrm{N}$ (2017) An exploration of facilitators and challenges in the scale-up of a national, public sector community health worker cadre in Zambia: A qualitative study. Human Resources for Health. Human Resources for Health 15(1): 1-9.

Pilang CL, Gray MA and Oprescu FI (2017) The evolution of the Community Health Worker program in Papua New Guinea. Rural \& Remote Health 17: 3961.

Profita AC (2018) Beberapa faktor yang berhubungan dengan keaktifan kader posyandu di desa pengadegan kabupaten banyumas. Jurnal Administrasi Kesehatan Indonesia. Universitas Airlangga 6(2): 68.

Rabbani F, Shipton L, Aftab W, Sangrasi K, Perveen S and Zahidie A (2016) Inspiring health worker motivation with supportive supervision: a survey of lady health supervisor motivating factors in rural Pakistan. BMC health services research 16(1): 397.

Raffo JE, Lloyd C, Collier M, Slater L, Cunningham B, Penninga K, Henning S, Coil J, Agee B, Quintino-Aranda V, VanderMeulen P and Roman LA (2017) Defining the Role of the Community Health Worker within a Federal Healthy 
Start Care Coordination Team. Maternal and Child Health Journal. Springer US 21(S1): 93-100.

Singh D, Cumming R and Negin J (2015) Acceptability and trust of community health workers offering maternal and newborn health education in rural Uganda. Health education research 30(6): 947-958. Available at: https://www.cochranelibrary.com/centra 1/doi/10.1002/central/CN01264683/full.

Strachan DL, Källander K, Nakirunda M, Ndima S, Muiambo A, Hill Z, Meek S, Tibenderana J, Castel-Branco AC, Kertho E, Strachan D, Kirkwood B, Soremekun S, Lingam R, Vassal A and Kasteng F (2015) Using theory and formative research to design interventions to improve community health worker motivation, retention and performance in Mozambique and Uganda. Human Resources for Health 13(1): 25.

Susanto F, Claramita M and Handayani S (2017) Peran kader posyandu dalam memberdayakan masyarakat Bintan. Berita Kedokteran Masyarakat 33(1): 13. Available at: https://jurnal.ugm.ac.id/bkm/article/vie w/11911.

Winn L, Lesser A, Menya D, Baumgartner J, Kipkoech Kirui J, Saran I and Prudhomme-O'Meara W (2018) Motivation and satisfaction among community health workers administering rapid diagnostic tests for malaria in Western Kenya. Journal of global health. Edinburgh University Global Health Society 8(1): 10401. 